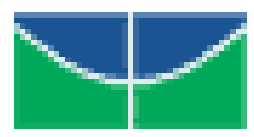

UNIVERSIDADE DE BRASÍLIA

Centro de Excelência em turismo

Pós-graduação Lato Sensu

Curso de Especialização em Gastronomia e Saúde

\title{
ACEITAÇÃO DO SAL DE ERVAS EM DIETA HIPOSSÓDICA
}

MICHELE DO NASCIMENTO BEZERRA

Orientadora: Prof. Msc. RENATA PUPPIN ZANDONADI

BRASÍLIA - 2008 


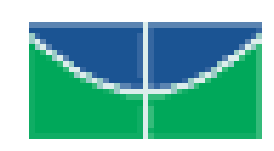

UNIVERSIDADE DE BRASÍLIA

Centro de Excelência em turismo

Pós-graduação Lato Sensu

Curso de Especialização em Gastronomia e Saúde

\title{
ACEITAÇÃO DO SAL DE ERVAS EM DIETA HIPOSSÓDICA
}

\author{
MICHELE DO NASCIMENTO BEZERRA
}

Orientadora: Prof. Msc. RENATA PUPPIN ZANDONADI

Monografia apresentada ao Centro de

Excelência em Turismo - CET, da

Universidade de Brasília - UNB como requisito

parcial para a obtenção de título de

Especialista em Gastronomia e Saúde. 
Bezerra, Michele Nascimento

Aceitação do sal de ervas em dieta hipossódica / Michele do

Nascimento Bezerra. - Brasília, 2008.

Monografia (especialização) - Universidade de Brasília, Centro de Excelência em Turismo, 2008.

Orientadora: Renata Puppin Zandonadi

1. Dieta hipossódica. 2. Sal. 3. Doenças Cardiovasculares 


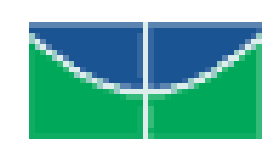

\section{UNIVERSIDADE DE BRASÍLIA}

Centro de Excelência em turismo

Pós-graduação Lato Sensu

Curso de Especialização em Gastronomia e Saúde

Monografia apresentada ao Centro de Excelência em Turismo - CET, da Universidade de Brasília - UNB como requisito parcial para a obtenção de título de Especialista em Gastronomia e Saúde

\section{ACEITAÇÃO DO SAL DE ERVAS EM DIETA HIPOSSÓDICA}

MICHELE DO NASCIMENTO BEZERRA

Aprovado por:

Professora orientadora:. Msc. RENATA PUPPIN ZANDONADI

Professora: Dr Raquel Assunção Botelho

Professora: Msc. Lívia Pinelli

Brasília, 10 de setembro de 2008. 


\section{AGRADECIMENTOS}

A Minha eterna gratidão a Deus, pela minha vida e por mais essa realização.

A minha professora orientadora Renata Puppin Zandonadi, por sua contribuição intelectual, dedicação e atenção ao meu trabalho.

Ao meu querido esposo Francisco, pelo companheirismo, amor, sorrisos e palavras amigas.

A minha mãe pela ternura, força, incentivo e amizade, que sempre acreditou no meu sucesso.

Aos professores do Curso de Gastronomia e Saúde pelos ensinamentos, que com certeza me engrandeceu profissionalmente. 


\section{SUMÁRIO}

RESUMO

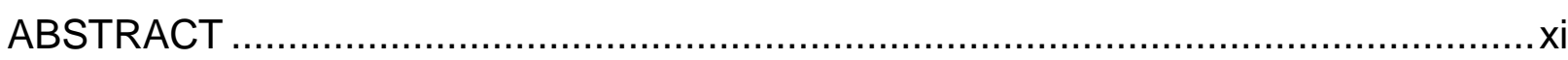

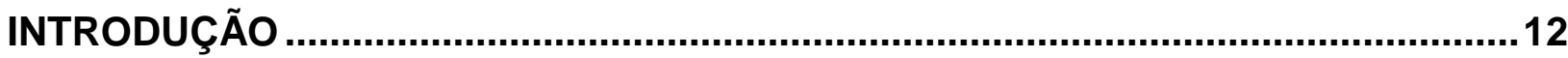

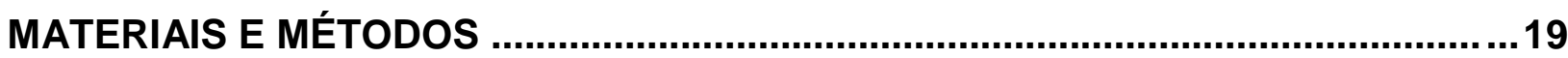

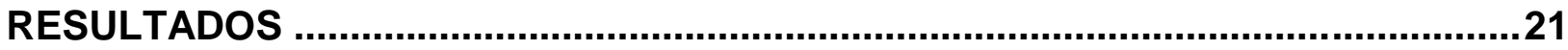

DISCUSSÃO

CONCLUSÃO

REFERÊNCIAS

APÊNDICES

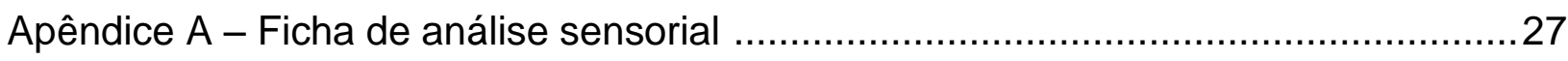

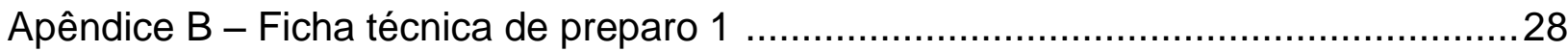

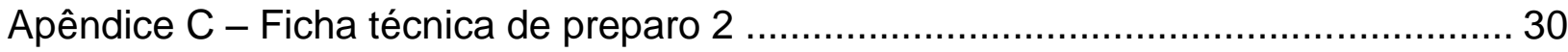

Apêndice D - Termo de consentimento ................................................................32 


\section{LISTA DE FIGURAS}

Figura 1. Faixa etária dos participantes da pesquisa .21

Tabela 1. Nota média de aceitação e porcentagens de aprovação, indiferença e rejeição dos feijões.

Figura 2. Notas atribuídas ao feijão hipossódico com sal de ervas e ao feijão padrão por pacientes internados 23 
Aceitação do sal de ervas em dieta hipossódica.

Acceptance of salt diet of herbs in hyposodic.

\section{Michele Nascimento BEZERRA}

Renata Puppin ZANDONADI ${ }^{1}$

\section{Resumo}

Objetivo: Buscou-se avaliar a aceitação do "sal de ervas" na dieta hipossódica oferecida a pacientes que necessitam restrição de sódio.

Métodos: Trata-se de um estudo transversal com 20 pacientes, sendo 13 homens e 7 mulheres, com idades entre 21 e 78 anos. As variáveis coletadas foram: nome, número do leito, idade, sexo, diagnóstico principal e presença de patologias que possam comprometer a percepção sensorial. Avaliou-se a aceitação do feijão temperado com sal de ervas, por meio de teste afetivo de aceitação com utilização de escala hedônica de sete pontos. Os resultados foram submetidos à Análise de Variância (ANOVA). Fixou-se nível de significância de $5 \%(p<0,05)$.

Resultados: Não foram encontradas diferenças significativas na aceitação do feijão padrão e do feijão acrescido de sal de ervas $(p=0,883)$. Dentre os pacientes participantes $50 \%$ eram cardiopatas, 10\% apresentavam insuficiência renal crônica e $35 \%$ apresentavam hipertensão. Foi verificada aprovação da preparação modificada por $80 \%$ dos pacientes e rejeição por $5 \%$. Já para a preparação padrão a aprovação foi de $75 \%$ e a rejeição de $15 \%$.

Conclusão: A substituição do tempero padrão na dieta hipossódica pelo sal de ervas é uma alternativa promissora, no entanto mais estudos são necessários para a verificação da real possibilidade da inserção do sal de ervas no ambiente médico hospitalar.

Termos de indexação: dieta hipossódica, sal, doenças cardiovasculares. 


\section{Abstract}

Objective: The aim was to assess the acceptance of the "salt of herbs" in the diet hyposodic offered to patients in need of sodium restriction.

Methods: This is a cross-sectional study with 20 patients, 13 men and 7 women, aged between 21 and 78 years. The variables were collected: name, number of bed, ages, sex, primary diagnosis and presence of diseases that could affect sensory perception. Was evaluated, the acceptance of beans seasoned with "salt of herbs" through emotional test of acceptance with the use of scale of seven points. The results were submitted to analysis of variance (ANOVA). Set up a significance level of $5 \%$

$(p$ $<0.05)$.

Results: No significant differences were found in the acceptance of the standard beans and beans plus "salt of herbs" ( $p=$. Among the participating patients were $50 \%$ cardiopathy, $10 \%$ had chronic renal failure and $35 \%$ had hypertension. It was verified approval of preparation modified for $80 \%$ of patients and rejection by $5 \%$. For standard preparation was verified $75 \%$ approval and $15 \%$ rejection. Conclusion: The replacement of standard salt, by "salt of herbs" is a promising alternative, though more studies are needed to verify the real possibility of inserting the "salt of herbs" in the hospital environment.

Indexing terms: hyposodic diet, salt, cardiovascular disease. 


\section{INTRODUÇÃO}

As doenças cardiovasculares contribuem como grupo causal para taxa de mortalidade em todas as regiões brasileiras. Além disso, constituem uma das principais causas de permanência hospitalar prolongada. O risco de desenvolver doença cardiovascular é avaliado com base na análise conjunta de características que aumentam a chance do indivíduo vir apresentar a doença, sendo que o conhecimento desses fatores de risco é de grande importância para o estabelecimento de estratégias de prevenção ${ }^{1}$. Porém vários são os fatores de risco que influenciam no aparecimento ou agravamento de doenças cardiovasculares em especial a hipertensão, tais como hereditariedade, idade, raça, sexo, obesidade e sobrepeso, ingestão elevada de sódio, sedentarismo, dietas ricas em gorduras².

Um dos fatores determinantes para ataques cardíacos e para derrames cerebrais é a elevada pressão arterial, causa mais comum de morte e incapacidade no mundo ocidental ${ }^{3}$. Apesar da grande variedade e disponibilidade dos agentes anti-hipertensivos disponíveis para o tratamento da HAS, menos de $1 / 3$ dos pacientes hipertensos adultos têm sua pressão adequadamente controlada. A não aderência ao tratamento deve ser entendida como o principal obstáculo para o sucesso do tratamento da HAS (Andrade et al, 2002). Contudo, esta mesma falta de controle da pressão arterial motiva a realização de estudos e pesquisas.

Os tratamentos farmacológicos e não farmacológicos, têm como finalidade prevenir a morbidade e mortalidade, bem como, a redução lenta e progressiva da pressão arterial, para aliviar os sintomas e diminuir as complicações ${ }^{2}$ advindas.

Alguns cuidados essenciais devem ser observados e estipulados aos detentores de HAS para que as conseqüências da hipertensão arterial sejam evitadas. O tratamento adequado varia de acordo com o quadro do paciente, no entanto, a restrição da ingestão dietética do sódio (principalmente o sal de cozinha - 
$\mathrm{NaCl}$ ) e do consumo de bebidas alcoólicas, bem como, a redução do peso corporal e a prática regular de atividades físicas, em alguns $\operatorname{casos}^{4}$ são vistos como suficientes.

Dados da Pesquisa de Orçamentos Familiares 2002-2003 - POF realizada pelo Instituto Brasileiro de Geografia e Estatística, indicam que a média estimada de consumo de sal domiciliar é de 9,6 gramas diários por pessoa. A partir de tais informações, estima-se que o consumo médio de sal pela população brasileira deve ser reduzido, pelo menos, à metade para atender ao patamar máximo de consumo recomendado pela Organização Mundial da Saúde - OMS, que é de 5 gramas de sal por dia 6 .

A hipertensão arterial é observada primeiramente em populações cuja ingestão de sal é superior a 100 miliequivalentes por dia ou 6 gramas de sal o que equivale a uma colher de chá; já em populações em que a ingestão de sal é inferior a 50 miliequivalentes diários, a hipertensão é rara ${ }^{7}$.

Devido ao exposto, o hábito alimentar dos hipertensos deve incluir redução da quantidade de sal na elaboração de preparações alimentícias; retirada do saleiro da mesa; restrição das fontes industrializadas de sal e utilização preferencial de temperos naturais como limão, ervas, alho, cebola, em substituição aos similares industrializados ${ }^{8}$.

Constatou-se que uma modesta diminuição de $\mathrm{NaCl}$, (de $10 \mathrm{~g}$ para $5 \mathrm{~g}$ por dia) provoca uma significante redução na pressão arterial, particularmente naqueles indivíduos com pressão arterial elevada. Outra comprovação já existente, é que quanto maior a redução do sal, maior será a diminuição da pressão sanguínea em hipertensos (primários ou secundários) e normotensos ${ }^{3}$. Apesar de necessária, a modificação dietética não é facilmente alcançada, pois o sal e a sua relação com a 
comida revelam representações simbólicas, culturalmente estabelecidas, de fácil acesso, baixo custo e alto poder de condimentação ${ }^{5}$.

Não há dúvidas de que níveis cronicamente elevados de pressão arterial estão associados à maior incidência de complicações cardiovasculares e renais. Sendo assim, o tratamento desta patologia se torna imprescindível e seu objetivo se torna reduzir o surgimento das citadas complicações, prolongando a sobrevida de pacientes hipertensos ${ }^{6}$.

A utilização de dieta com reduzido conteúdo de sódio é um dos principais e mais baratos tratamentos para pacientes portadores de hipertensão arterial, porém, para ingestão e aceitação da dieta hipossódica, é necessária alteração no estilo de vida do paciente, que com muita freqüência apresenta resistência às mudanças, principalmente por aspectos culturais intrínsecos e queixas relativas à falta de sabor dos alimentos ${ }^{5}$. A não ingestão da dieta recomendada pode conduzir os pacientes (principalmente os internados) a não ingerirem os alimentos oferecidos e levar a um quadro de desnutrição com conseqüente piora do quadro clínico.

Muitos pacientes com restrição alimentar reportam que a dieta é a parte mais difícil do tratamento, devido a mudanças nas preferências alimentares e alterações no estilo de vida. A dificuldade na adesão à dieta hospitalar pode agravar o estado de saúde do paciente e aumentar os custos para o hospital, devido ao aumento do tempo de internação. A falta de eficiência terapêutica em conseqüência da inadequação à dieta também pode ocorrer quando uma substância alimentar retarda ou reduz a absorção do medicamento, acelera sua taxa de metabolização, ou impede seu efeito mediante algumas interações farmacodinâmicas ${ }^{9}$.

Um estudo realizado ${ }^{10}$, demonstrou que de $36 \%$ a $78 \%$ dos pacientes internados são desnutridos. Deste modo, além da identificação de pacientes em risco nutricional, deve-se estar atento para que a ingestão alimentar assegure ao 
paciente a quantidade e os tipos de alimentos adequados às suas expectativas e necessidades principalmente nutricionais e sensoriais.

A aceitação da alimentação por parte do paciente internado é decisiva para uma ação efetiva da dietoterapia, que é a parte do tratamento e envolve modificações na alimentação, adequando-a a situação patológica do enfermo.

A contribuição terapêutica nutricional é comprovada por meio de inúmeras pesquisas, que demonstram o aumento da incidência de complicações infecciosas no paciente desnutrido com conseqüente aumento do tempo de internação exigindo cuidados intensivos. Outros fatores para redução da ingestão alimentar são: a distância da família, horário e sabor da alimentação.

O conhecimento desses fatores deve constituir o ponto de partida para 0 desenvolvimento de estratégias, no sentido de evitar a ocorrência de fatores inerentes ao serviço que interfiram na aceitação do paciente, minimizando, desta maneira, a ocorrência de elementos que influenciem negativamente a terapêutica nutricional ${ }^{11}$.

Deste modo, em adição a identificação de pacientes em risco nutricional, deve-se também estar atento para que a ingestão alimentar assegure a quantidade e os tipos de alimentos adequados às suas expectativas e necessidades ${ }^{10}$.

A adaptação ao cardápio oferecido no hospital, ao ambiente de refeição e às emoções envolvidas na satisfação do paciente pode melhorar a aceitação alimentar e com isso, suprir as necessidades do indivíduo ${ }^{12}$. Assim, as alterações referentes ao padrão alimentar devem ser consideradas na abordagem do paciente de hipertensão arterial, com intuito de desmistificar a idéia de dieta como uma alimentação restritiva, de sabor desagradável e sem atrativos sensoriais. Portanto, destacam-se a modificação nas técnicas de preparo dos alimentos, a substituição de ingredientes e a utilização de ervas e temperos naturais ${ }^{12}$. 
O sal, além de conferir sabor, também está relacionado a uma maior sensação de saciedade por períodos mais prolongados, especialmente manifestados por pessoas envolvidas com trabalhos braçais. Na compreensão destes aspectos, entende-se que a adoção de modificações de hábitos de vida não é fácil; entretanto, é possível principalmente por um processo de educação, abordado de forma multidisciplinar e não considerando somente aspectos técnicos do tratamento não farmacológico, visto ser o sabor salgado um hábito adquirido ${ }^{5}$.

Para aumentar a adesão às condutas preconizadas pelo tratamento, os pacientes devem receber orientações sobre a doença, com conteúdos simples e educativos, para maior entendimento e também, orientações culinárias para realçar o sabor das refeições a partir da diminuição da quantidade de sal. ${ }^{12}$

Conforme Batista et $\mathrm{al}^{12}$, nas restrições modernas e severas de sódio é recomendado o uso de condimentos caseiros para melhorar a palatabilidade do alimento. A substituição do sal pode ser realizada por salsa, cebola, cebolinha, alho, vinagre, limão, hortelã, coentro, manjericão, folhas de mostarda, louro, páprica, orégano e alecrim, entre outros.

Por definição, condimentos e especiarias são vegetais possuidores de substâncias aromáticas ou picantes de origem tropical, usadas para dar sabores e odores aos alimentos. Esses incluem folhas, caules, flores e germinações, bulbos, rizomas, e outras partes das plantas ${ }^{14}$. Além desta utilidade, possuem também, propriedades antimicrobianas, antioxidantes e medicinais ${ }^{15}$.

Os componentes provedores de sabores existentes nas especiarias consistem em compostos como álcoois, ésteres, aldeídos, terpenos, fenóis, ácidos orgânicos dentre outros elementos, ainda não identificados por completo ${ }^{16}$.

Segundo a RDC 276 de 2005, a utilização de espécie vegetal, parte de espécie vegetal ou ingrediente que não é usada tradicionalmente como alimento 
pode ser autorizada, desde que seja comprovada a segurança de uso do produto, em atendimento ao Regulamento Técnico específico ${ }^{17}$.

Os temperos e as especiarias têm sido amplamente utilizados desde as civilizações antigas como agentes provedores de características organolépticas favoráveis aos alimentos aos quais são adicionadas. Dessa forma, a utilização de substâncias naturais, de origem vegetal, torna o alimento mais atrativo ao consumidor $^{13}$.

O orégano (Origanum vulgare $L$ ) consiste em uma erva originária do mediterrâneo, muito cultivada também na Turquia e Chile. Trata-se de uma das mais aromáticas e conhecidas ervas da cozinha brasileira. Sua utilização acontece principalmente em molhos de tomate, pizzas, saladas e tempero de aperitivos ${ }^{18}$.

O manjericão (Ocimum basilicum L) constitui uma erva fortemente aromática, com sabor característico. Na Grécia Antiga é conhecido como erva dos reis. Seu sabor combina bastante com tomate, hortaliça em que é amplamente utilizado, tanto em saladas quanto em molhos ${ }^{19}$.

O alecrim (Rosmarinus officinalis L.) possui aroma forte e gosto adocicado e acentuado. Originária da Europa Central a erva é utilizada em discreta quantidade em assados, aves, caça e especialmente no assado de cordeiro ${ }^{18}$.

O feijão, leguminosa com origem nos Andes e na Mesoamérica (há vestígios de cerca de 7 mil anos a.C. no México e de até 10 mil anos a.C. no Peru, no sítio de Guitarrero) foi uma das plantas alimentícias mais importantes dessas sociedades, talvez a sua maior fonte de proteínas ${ }^{19}$.

Atualmente, no Brasil o arroz e o feijão aparecem no cardápio diário combinados a diversas preparações, massas, hortaliças, carnes e frutos do mar, compondo o hábito alimentar dos brasileiros ${ }^{20}$. 
O "sal de ervas" (preparado com partes iguais de sal, alecrim desidratado, manjericão fresco, orégano desidratado) ajuda na diminuição de sal absoluto e agrega propriedades antioxidantes e antiinflamatórias provenientes de substâncias bioativas encontradas nas ervas. A associação dos fitoquímicos com o sal produto tão aceito na mesa da população favorecem para o tratamento e prevenção das doenças cardiovasculares. A mistura pode ser acrescida em qualquer preparação em substituição ao sal realçando o sabor do alimento.

O sal, como fonte de sódio, não deve ser retirado totalmente da dieta, por ser um mineral importante no controle de líquidos celulares, além de desempenhar um papel de conservação dos alimentos. Por isso, o mais importante é controlar sua ingestão e não eliminá-lo totalmente da dieta ${ }^{21}$.

Os alimentos com alegação de propriedade funcional ou de saúde têm sido muito estudados e apresentam substâncias bioativas que podem prevenir ou reduzir o risco de alguma patologias ou auxiliar no seu tratamento. Entre as mais investigadas, estão as cardiovasculares, câncer, hipertensão, diabetes, doenças inflamatórias intestinais, e outras. As ervas presentes no composto "Sal de Ervas" além de realçar o sabor dos alimentos são consideradas também alimentos nutracêuticos, pois proporciona benefícios à saúde, incluindo a prevenção e/ou tratamento da doenças principalmente cardiovasculares por auxiliar na redução do processo inflamatório e oxidativo ${ }^{22}$.

As ervas evitam monotonia à mesa, têm o poder de perfumar os alimentos e ainda trazem vários benefícios à saúde.

No tratamento da hipertensão arterial, a gastronomia, (enquanto arte do sabor, prazer e bom gosto) deve se aliar a dietoterapia, como ciência do plano alimentar, visando a melhor adesão à terapia nutricional e promovendo melhor qualidade de vida ${ }^{5}$. 
Portanto, buscou-se avaliar a aceitação do "sal de ervas" na dieta hipossódica oferecida a pacientes internados em um hospital privado de Brasília/DF, que necessitam restrição de sódio, a fim de se prevenir a inapetência dos indivíduos submetidos a essa alimentação.

\section{MATERIAIS E METÓDOS}

Trata-se de um estudo transversal quantitativo desenvolvido no Hospital Brasília - HOBRA, localizado na QI 15 do lago sul na cidade de Brasília - DF.

A amostra foi selecionada por conveniência. Para sua determinação foi realizado um levantamento dos prontuários de todos os pacientes internados que recebiam dieta hipossódica como tratamento dietoterápico.

Foram excluídos da amostra os pacientes em terapia intensiva, inapetentes, com queixas gastrointestinais (náuseas, vômitos, diarrérias) e desorientados. Também foram excluídos indivíduos com idade inferior a 18 anos ou superior a 80 anos.

As variáveis coletadas foram: nome, número do leito, idade, sexo, diagnóstico principal e presença de patologias que possam comprometer a percepção sensorial.

O teste foi aplicado nos dias 29 e 30 de agosto e nos dias 05 e 09 de setembro do ano de 2008. O número de amostras preparadas por dia foi determinado de acordo com o número de pacientes internados que encaixavam no perfil da pesquisa. No decorrer dos quatro dias de aplicação de testes foram totalizados 20 participantes.

O estudo foi realizado em duas etapas, a primeira consistiu na modificação da preparação feijão com adição de sal de ervas e a segunda em teste afetivo quantitativo com utilização de escala hedônica de sete pontos.

Inicialmente realizou-se a padronização do feijão preparado na cozinha dietética da Unidade de Alimentação e Nutrição - UAN do hospital, através da elaboração de ficha técnica de preparação ${ }^{25}$ (Anexos B e C ).

Uma vez que fichas técnicas de preparação propiciam vários benefícios para todas as categorias no processo de produção, facilita o trabalho do profissional de nutrição, promove aperfeiçoamento dos funcionários e, principalmente, permite 
controlar o valor energético total e nutrientes fornecidos pelos alimentos a padronização do feijão foi realizada através das mesma ${ }^{23}$.

O sal de ervas foi preparado com $25 \%$ de sal refinado de cozinha, $25 \%$ de orégano desidratado, $25 \%$ de manjericão desidratado e $25 \%$ de alecrim desidratado. O feijão com sal padrão recebeu como tempero, além do alho e óleo, o sal refinado de cozinha. O feijão com sal de ervas foi temperado com quantidade equivalente de tempero, porém foi utilizado o sal com ervas, além do alho e do óleo.

Foi estipulada porção de 40 gramas de feijão para cada amostra. Essa foram distribuídas em copos plásticos de 100ml, transparentes e com tampas. Os recipientes foram codificados com três dígitos (351 para o feijão hipossódico padrão, 248 para o feijão hipossódico adicionado com sal de ervas).

Os testes sensoriais foram realizados nos leitos sempre no horário intermediário entre a colação e o almoço para evitar interferência com as demais refeições. As duas preparações foram oferecidas na mesma temperatura $\left(65^{\circ} \mathrm{C}\right)$ em uma única visita. Primeiro foi ofertado o feijão com sal de ervas e depois o feijão com sal padrão.

Entre a degustação das duas preparações os pacientes foram orientados a ingerir água mineral para eliminação do sabor da preparação anterior. Após a degustação das duas preparações os participantes atribuíram notas para cada uma delas.

Cada participante assinou o termo de consentimento para a participação da pesquisa no ato da coleta, o qual se encontra no anexo D.

A análise sensorial foi realizada por meio de teste afetivo de aceitação com utilização de escala hedônica de sete pontos variando de 7-gostei muitíssimo a 1desgostei muitíssimo (Anexo 1). Na ficha para análise sensorial foi perguntado ainda sobre a apreciação de ervas como tempero de alimentos.

Os resultados de aceitação foram submetidos à Análise de Variância (ANOVA), considerando estatisticamente significativo $p<0,05$. 


\section{RESULTADOS}

Participaram da pesquisa 20 indivíduos. Dos quais 13 homens e 7 mulheres. Com relação as doenças apresentadas pelos pacientes $50 \%$ eram cardiopatas, $10 \%$ apresentavam insuficiência renal crônica e 35\% apresentavam hipertensão. Todos recebiam dieta hipossódica padrão durante a internação.

A faixa etária dos participantes da pesquisa encontra-se na figura 1.

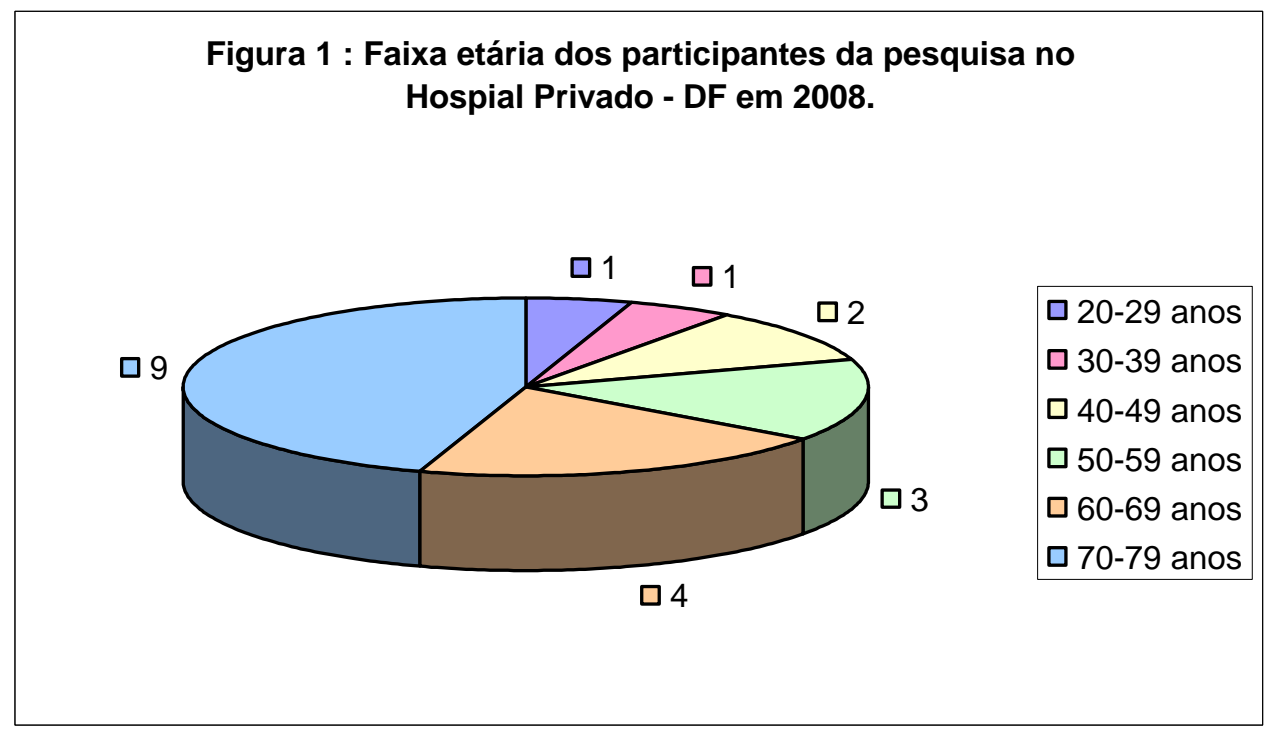

A maioria dos participantes da pesquisa possui 70 anos ou mais, correspondendo a um percentual de 45 \%. É característico da população interna do hospital estudado a maior prevalência de pessoas idosas no número de internações totais realizadas.

Para a dieta hipossódica padrão é enviado 1 grama de sal para adição nas preparações. Sabe-se que a maior parte dos pacientes utiliza esse ingrediente associado ao feijão por ser um produto de mais fácil mistura e de grande rejeição quando não apresenta sal ${ }^{5}$. Portanto, a adição dessa quantidade de sal contribui para o incremento de 387,6mg de sódio na porção do feijão além do sódio intrínseco a leguminosa. Em comparação com a quantidade de sódio presente no feijão adicionado de sal de ervas $(103,5 \mathrm{mg})$, observa-se que houve redução de $73 \%$ de sódio (Anexo B e C).

Considerando que o almoço corresponde a $35 \%$ do $\operatorname{VET}^{25}$ diário e a quantidade de sódio recomendada é de $2400 \mathrm{mg}$ de sódio por dia $^{26}$, estima-se que a contribuição de sódio por esta refeição deve ser de 840mg de sódio. 
Sabendo que o sódio do almoço é distribuído em prato principal, acompanhamentos e guarnição, porcionou-se igualmente os $840 \mathrm{mg}$ de sódio entre as quatro preparações e verificou-se que, para cada preparação ficariam disponíveis $210 \mathrm{mg}$ de sódio.

Dessa forma verifica-se que a oferta de 1 grama de sal para o paciente com dieta hipossódica garante valores diários de sódio inferiores ao recomendado.

Mesmo com a adequação do sódio encontrada no serviço hospitalar, foi verificada a aceitação do feijão temperado com o sal de ervas. A tabela 1 apresenta os valores encontrados.

Tabela 1. Nota média de aceitação e porcentagens de aprovação, indiferença e rejeição dos feijões.

\begin{tabular}{lcccc}
\hline \multicolumn{1}{c}{ Tipo } & Média* $^{*}$ & $\%$ de aprovação** & $\%$ de indiferença** & \%de rejeição** \\
\hline Modificado & 5,3 & $80 \%$ & $10 \%$ & $5 \%$ \\
Padrão & 5,1 & $75 \%$ & $5 \%$ & $15 \%$ \\
\hline * Média dos provadores & & & \\
** \% de aprovação= porcentagem de notas 5 a $7 ; \%$ de indiferença= porcentagem de nota $4 ; \%$ de \\
rejeição= porcentagem de notas de 1 a 3.
\end{tabular}

De maneira geral, as médias globais das notas dos feijões não apresentaram diferença significativa entre as amostras quanto à aceitação $(p=0,883)$. Todavia as duas médias são de boa aceitação. Tanto para o feijão modificado quanto para 0 padrão as notas correspondem ao termo hedônico gostar ligeiramente. Na figura 2 estão as notas atribuídas às preparações ofertadas para os pacientes com dieta hipossódica. 


\section{Figura 2: Notas atribuidas ao feijão hipossódico com sal de ervas e ao feijão padrão por pacientes internados no Hospital -DF, 2008.}

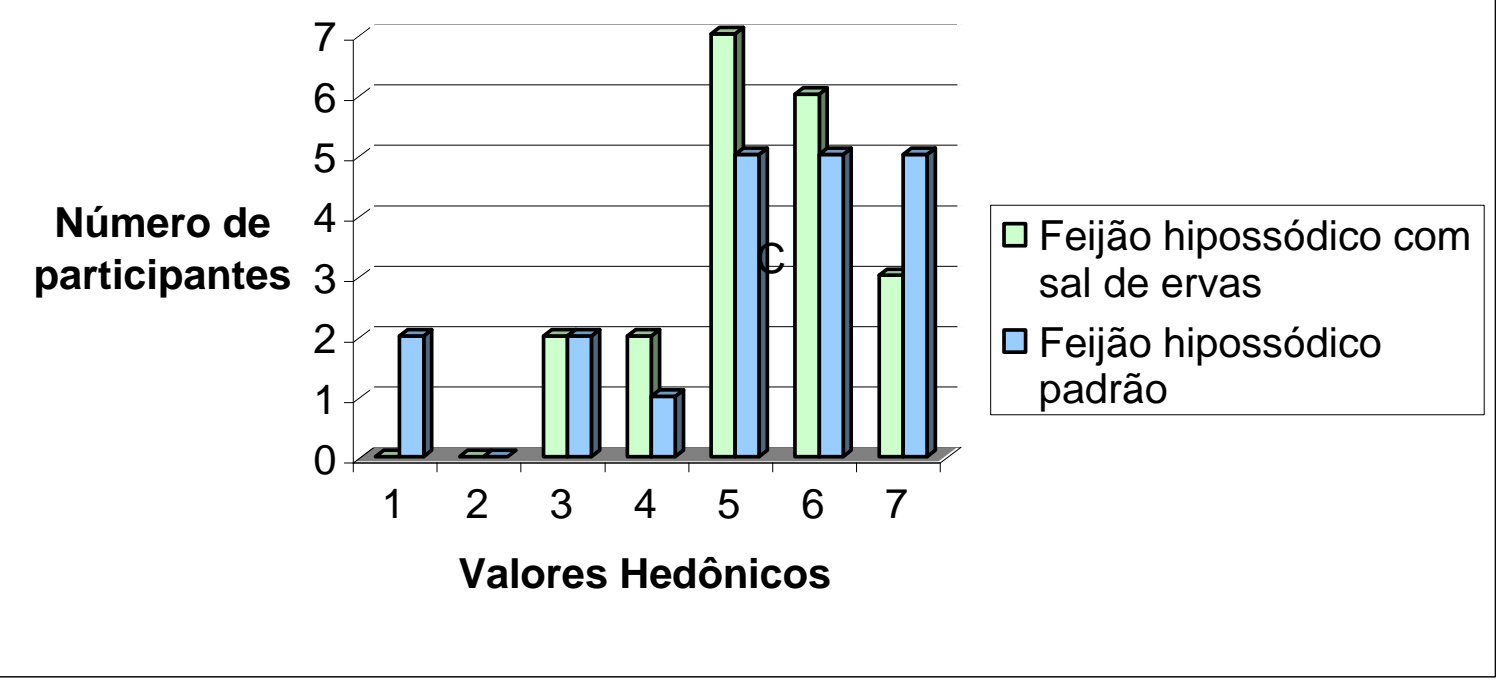

Quanto ao questionamento de apreciação de ervas para utilização como tempero de preparações, $100 \%$ dos participantes responderam de forma positiva.

\section{DISCUSSÃO}

A ocorrência de $50 \%$ de internações por doenças cardiovasculares corrobora com os dados atuais do $\mathrm{SUS}^{3}$. Tal fato reforça a grande incidência de doenças crônicas não transmissivas, as quais desde a década de 30 vem substituindo as doenças infecciosas em número de internações e óbitos ${ }^{21}$.

Um estudo realizado por Amaral et $\mathrm{al}^{22}$, mostrou que as doenças cardiovasculares consistiam na principal causa de internação de idosos no país. $\mathrm{Na}$ amostra coletada no estudo em questão tal fato ocorre novamente.

A diminuição do teor de sódio em 73\% na amostra com o sal de ervas foi possível através da utilização de especiarias. Isso porque condimentos e especiarias são produtos aromáticos de origem vegetal empregados para conferir sabor aos alimentos, além de promoverem benefícios à saúde ${ }^{13}$.

Considerando que o consumo máximo de sódio do paciente por dia seja $2400 \mathrm{mg}$ e que o almoço corresponda a 35\% do valor energético diário, obtem-se quantidade de $840 \mathrm{mg}$ de sódio para ser utilizado nessa refeição. Uma vez que o sal é distribuído entre prato principal, acompanhamentos e guarnição, existe a possibilidade de aumentar a oferta de sódio da dieta. A adição de sal as demais 
preparações pode melhorar a aceitabilidade da dieta e assim o prognóstico do paciente.

No decorrer do teste de aceitabilidade foi observada grande variação em relação à aceitação das preparações. A princípio acreditava-se que tal fato devia-se a não apreciação de ervas pela população em geral. No entanto quando questionados a respeito da apreciação de ervas no preparo de refeições, $100 \%$ dos pacientes responderam positivamente.

O feijão hipossódico padrão, temperado com alho e sal, apresenta um aroma característico, podendo ser bem perceptível a presença do alho, o que foi relatado pelos pacientes que apreciaram a preparação. Já para o feijão com sal de ervas foi relatado sabor adocicado e especial, positivo para a palatabilidade da preparação, entre os pacientes que aprovaram tal a mesma.

Acredita-se que o feijão adicionado de "sal de ervas" consiste em uma alternativa promissora para a dieta hipossódica. No entanto, devido a não existência de diferenças estatísticas entre a aceitação dos feijões, é necessário verificar a adequação da quantidade de sal de ervas e de sal padrão utilizados e seu reflexo no sabor das preparações para otimizar sua utilização.

É fundamental testar a aceitação de novos temperos para a dieta hipossódica e orientar a população em relação as características da mesma. Nesse exercício a gastronomia deve ser evidenciada enquanto arte do sabor e o atendimento nutricional individualizado deve ocorrer objetivando a melhor aceitação da dieta pelo paciente. 


\section{CONCLUSÃo}

Observou-se que a substituição do tempero padrão na dieta hipossódica pelo sal de ervas é uma alternativa promissora, visto que o produto proporciona características sensoriais favoráveis, interferindo positivamente na aceitabilidade do paciente.

A utilização do sal de ervas, além da aprovação dos pacientes é favorável, uma vez que o teor de sódio de tal tempero é reduzido em 73\%. Dessa forma, o sal de ervas além de promover sabor e odor agradáveis ao alimento é responsável pela diminuição do sódio na dieta com restrição desse micronutriente.

As modificações técnicas de preparo dos alimentos, a substituição de ingredientes e a utilização de ervas e temperos naturais, nesse sentido, surgem como alternativas para melhorar a adesão à terapia nutricional e promover uma melhora na qualidade de vida do paciente.

No entanto mais estudos são necessários para a verificação da real possibilidade da inserção do sal de ervas no ambiente médico hospitalar. 


\section{REFERÊNCIAS BIBLIOGRÁFICAS}

1- CASTRO, L. C.; FRANCESCHINI, S. C.; PRIORE, S. E.; PELÚZIO, M. C. Nutrição e doenças cardiovasculares: marcadores de risco em adultos. 2004

2- BATISTA, L.; CARVALHO, L. Hábitos de saúde e fatores de risco em pacientes hipertensos. Universidade de São Paulo, 2002.

3- GRAHAM A.; MAC GREGOR, FRPC. Salt, hipertension, and cardiovascular disearse. E.U.A. 2001.

4- HADDY F. Role of dietary sal in hypertension. E.U.A.2005.

5- DALLEPIANE, L. B.; BÓS, A. J. G. 0 uso de condimentos na dieta em um grupo de hipertensos: estudo de intervenção randomizado. Departamento de Ciências da Saúde da Unijuí. 2007.

6. Brasil. Ministério da Saúde. Secretaria de Atenção à Saúde. Coordenação-Geral da Política de Alimentação e Nutrição. Guia alimentar para a população brasileira, Brasília -DF, Série A. Normas e Manuais Técnicos:, 2005.

7. Krauss RM, Eckel RH, Howard B, Appel LJ, Daniels SR, Deckelbaum RJ, et al. Dietary Guidelines: revision 2000: A statement for healthcare professionals from the Nutrition Committee of the American Heart Association. Circulation 2000;102:2284-99.

8. Brandão A, Machado CA, Amodeo C, Mion Junior D, Nobre F, et al. V Diretrizes Brasileira de Hipertensão [on line] 2006; [Acesso em: 05 de setembro de 2008];

Disponível em:

http://www.sbh.org.br/novo/template2.sp?id=profissional documentos. 
9- RIBEIRO, A. S.; MELLO, E. D.; DREHMER, M. SIMON, M.I.S.S.; Levantamento do número de pacientes do Hospital das Clínicas de Porto Alegre que consomem alimentos não fornecidos pelo hospital. Revista HCPA, 2007

10- YABUTA, C. Y; CARDOSO, E; ISOSAKI, M. Dieta Hipossódica: aceitação por pacientes internados em hospital especializado em cardiologia. 2005.

11- MORIMOTO, I. M. I; Melhoria da qualidade na unidade de alimentação e nutrição hospitalar: um modelo prático. Universidade Federal de Santa Catarina, 2002.

12- MONEGO, E. T.; MAGGI, C. Gastronomia na promoção da saúde dos pacientes hipertensos. Revista Brasileira de Hipertensão, 2004.

13. BATISTA, SMM: CARVALHO, T. In BOREINSTAIN, M., Susskind. Organização. Manual de Hipertensão. Porto Alegre: Editora Sagra Luzzato, 1999.

14. BEDIN, C.; GUTKOSKI, S.B.; WIEST, J.M. Atividade antimicrobiana das especiarias. Higiene Alimentar, 1999. 13: 26-29.

15. PEREIRA, MC.; VILELA, GR; COSTA, LMAS.; SILVA, RF.; FERNANES AF., FONSECA, EWN, et al. Inibição do desenvolvimento fúngico através da utilização de óleos essenciais de condimentos. Ciênc. agrotec., Lavras, 2006

16. BAYDAR, H.;SAGDIC, O.;OZAKAN, G.; KARADOGAN, T. Antibacterial activity and composition of essential oils from Origanum, Thymbra and Satureja species with commercial importance in Turkey. Food Control, 2004. 15: 169-172,

17. ANVISA - Agência Nacional de Vigilância Sanitária. Aprova o "regulamento técnico para especiarias, temperos e molhos". Resolução de diretoria colegiada. RDC n‥ 276, de 22 de setembro de 2005.

18. CORAZZA S, Aromacologia: uma ciência de muitos cheiros. $1^{\text {a }}$ edição. São Paulo. Senac, 2002. 412 p.

19. CARNEIRO, H. Comida e sociedade: significados sociais na História da Alimentação. História Questões e Debates, Curitiba-PR, 2005. v. 42, p. 71-80. 
20. BARBORSA, L. Feijão com arroz e arroz com feijão: o Brasil no prato dos brasileiros. Horiz. antropol., July/Dec. 2007, vol.13, no.28, p.87-116.

21. GUYTON, A. C. Fisiologia Humana. México, D. F. 6 ed. 1987.

22. MORAES, F. P.; COLLA, L. M.; Alimentos funcionais e nutracêuticos: Definições, legislação e benefícios à saúde. Revista Eletrônica de Farmácia, 2006.

23. AKUTSU, R. C.; BOTELHO, R. A.; CAMARGO, E. B.; SAVIO, K.; ARAÚJO, W. M. A ficha técnica de preparação como instrumento de qualidade na produção de refeições. Rev. Nutr., Mar/Apr. 2005, vol. 18

24. TEXEIRA, S; OLIVEIRA, Z.M.C. Administração Aplicada às Unidades de Alimentação e Nutrição. São Paulo: Atheneu, 2007.

25- CAMARGO, E. B.; BOTELHO, R. A. Técnica dietética - Seleção e preparo dos alimentos - Manual de laboratório. 1 ed.: São Paulo: Atheneu, 2005. 


\section{APÊNDICE A \\ FICHA DE ANÁLISE SENSORIAL \\ Universidade de Brasília \\ Centro de Excelância em Turismo \\ Curso de Especialização Gastronomia e Saúde}

\section{TESTE DE ANALISE SENSORIAL}

\section{Amostra 248}

Sexo:

Idade:

Diagnóstico:

Por favor, avalie o feijão e/ou sopa utilizando a escala abaixo para descrever o quanto você gostou ou desgostou do produto. Marque a posição da escala reflita seu julgamento.

Código da amostra:
(7) Gostei muitíssimo
(6) Gostei moderadamente
(5) Gostei ligeiramente
(4) Indiferente
(3) Desgostei ligeiramente
(2) Desgostei moderamente
(1) Desgostei muitíssimo
( ) Avaliação geral do produto
( ) Sabor
( ) Cor
( ) Odor
( ) Temperatura

Comentários sobre a dieta hipossódica:

TESTE DE ANALISE SENSORIAL

Amostra 351

Sexo:

Diagnóstico:

Idade:

Por favor, avalie o feijão e/ou sopa utilizando a escala abaixo para descrever o quanto você gostou ou desgostou do produto. Marque a posição da escala reflita seu julgamento.

Código da amostra:

(7) Gostei muitíssimo

(6) Gostei moderadamente

(5) Gostei ligeiramente

(4) Indiferente

(3) Desgostei ligeiramente

(2) Desgostei moderamente

(1) Desgostei muitíssimo

( ) Avaliação geral do produto

( ) Sabor

( ) Cor

( ) Odor

( ) Temperatura

Comentários sobre a dieta hipossódica: 


\section{APÊNDICE D}

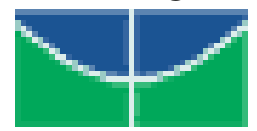

Universidade de Brasília

Centro de Excelância em Turismo

\section{Curso de Especialização Gastronomia e Saúde}

\section{TERMO DE CONSENTIMENTO LIVRE E ESCLARECIDO}

(Em duas vias, sendo uma para o sujeito de pesquisa)

Você está sendo convidado(a) como voluntário(a) a participar da pesquisa intitulada "Aceitação do sal de ervas em dieta hipossódica".

O propósito desta pesquisa é avaliar a aceitação de sal de ervas nos pacientes que recebem dieta baixa em sódio, a fim de melhorar a qualidade nutricional e sensorial da dieta hipossódica.

Os dados serão coletados por meio da aplicação de ficha de análise sensorial com escala hedônica de 7 pontos. Os participantes provarão e atribuirão notas de 1 a 7 para as preparações ofertadas, sendo 1 desgostei muitíssimo e 7 gostei muitíssimo.

Aqueles que fornecerem dados espontaneamente pós-esclarecimento terão suas identidades preservadas mesmo após elaboração de relatório final deste estudo.

O resultado deste estudo poderá possibilitar ou não modificações sensoriais dos alimentos fornecidos para pacientes com restrição de sódio, melhorando a aceitação da dieta hiposódica.

Este projeto foi aprovado pelo Comitê de Ética em Pesquisa do Centro Universitário Unieuro. Este termo em duas vias é para certificar que eu,

residente à concordo

em participar voluntariamente da pesquisa mencionada e sei que posso retirar meu consentimento a qualquer momento, sem nenhum prejuízo.

Estou ciente de que a pesquisa não implicará em riscos físicos à minha pessoa nem à instituição da qual faço parte.

Finalizando, sou sabedor de que terei todas as dúvidas respondidas a contento pelo pesquisador responsável , no telefone ou e-mail

Assinatura do sujeito de Pesquisa

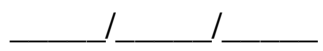


